\title{
From Bench to Bedside
}

\section{From Bench to Bedside: No Need to be Nervous About Microsuturing?}

\author{
Benjamin K. Potter MD, FACS
}

$\mathrm{P}$ eripheral nerve injuries, whether sustained through avulsive neurotmesis, sharp or projectile penetrating mechanisms, or iatrogenic injury, can be devastating. Ignoring for a moment the miraculous physiologic complexities of our muscular and skeletal symptoms, individual muscles and bones are, quite frankly, "dumb," providing a specific and limited set of mechanical functions. Peripheral nerves, on the other hand, are dizzyingly complex-carrying critical afferent and efferent information along

A note from the Editor-in-Chief:

I am pleased to present the next installment of

"From Bench to Bedside," a quarterly column written by Benjamin K. Potter MD.

Dr. Potter is a clinician-scientist in the Uniformed Services University-Walter Reed Department of Surgery. His column investigates important developments that are making —or are about to make-the transition from the laboratory to clinical practice, as well as technologies and approaches that have recently made that jump.

The institution of the author (BKP) has received, during the study period, funding and personnel support from the Major Extremity Trauma Research Consortium (METRC). All ICMJE Conflict of Interest Forms for authors and Clinical Orthopaedics and Related Research ${ }^{\circledR}$ editors and board members are on file with the publication and can be viewed on request.

The opinions expressed are those of the writers, and do not reflect the opinion or a living system of electrical circuits that we take for granted during any activity we do, and even during our periods of inactivity. Despite the perceived predilection to injury, our nerves are quite robust - the majority of nerve tissue being biological insulation in the form of myelin sheaths and vascularized connective tissue that supports and nourishes our nerves, allowing them to glide within our limbs so that we don't cause a nerve palsy during strenuous or contorted activities.

policy of $C O R R^{\circledR}$ or The Association of Bone and Joint Surgeons ${ }^{\mathbb{R}}$.

The author is an employee of the US Government and this work was prepared as part of his official duties. As such, there is no copyright to transfer. The views expressed in this article are those of the author and do not necessarily reflect the official policy or position of the Department of the Army, Department of the Navy, Department of Defense, nor the US Government. I certify that all individuals who qualify as authors have been listed; each has participated in the conception and design of this work, the analysis of data, the writing of the document, and the approval of the submission of this version; that the document represents valid work; that if I used information derived from another source, I obtained all necessary approvals to use it and made appropriate acknowledgements in the document; and that each takes public responsibility for it. Nothing in the presentation implies any Federal/DOA/DON/DOD endorsement. The
Historically, the prognosis for complete nerve injuries (either internal or external transections) has not been spectacular. Yes, direct repairs can sometimes restore nerve function rather dramatically, particularly for distal injuries in younger patients. However, proximal injuries, in mixed motor and sensory nerves, and/or involving "critical-sized" defects of 4 $\mathrm{cm}$ to $7 \mathrm{~cm}$ or longer, continue to be challenging, and the prognosis remains poor for most patients who experience these injuries.

Numerous advances in the last two decades have finally started to "move the needle" and improve the prognosis for the surgical management of peripheral nerve injuries. Viable offthe-shelf surgical conduits for shortsegment gaps (or for overwrapping

author received no financial support for this editorial.

\section{B. K. Potter MD, FACS}

Orthopaedic Surgery, Uniformed

Services University -Walter Reed

Department of Surgery, Bethesda, MD, USA

B. K. Potter MD, FACS ( $\square)$

Walter Reed National Military Medical

Center, 8901 Wisconsin Ave, America

Building (19), 2nd Floor - Ortho,

Bethesda, MD 20889, USA

e-mail: Benjamin.k.potter.mil@mail.mil 


\section{From Bench to Bedside}

repair sites to limit scarring and axonal escape) have become widely available, and offer results comparable to direct repair for short-segment deficits, particularly for sensory nerves $[4,6]$. Perhaps better still, decellularized human allograft nerve grafts (Avance, AxoGen, Inc, Alachua, FL, USA) have demonstrated meaningful sensory and motor recovery (M4-M5, representing near-normal to normal strength against resistance), potentially equivalent to autograft (or even direct repair [10]) without donor site limitations or morbidity, for defects as long as $5 \mathrm{~cm}[1,6$, 7]. Investigators have focused with renewed enthusiasm on the immunosuppressant FK506 (tacrolimus) based on better-than expected neurologic recovery in patients undergoing wholehand transplants [2]. Tacrolimus appears to enhance nerve regeneration through a noncalcineurin dependent pathway, and has been studied intermittently for decades for this purpose $[12,13]$. Perhaps most exciting, we may finally be approaching the event horizon of the era of sutureless (or minimal-suture) nerve repair.

Why the need for minimal suture nerve repair? Microsuturing of nerves is fraught with difficulty, and can result in undesired complications such as scarring, fascicle ligation by the suture, or gapping and axonal escape resulting in a neuroma in continuity, particularly when not augmented with a nerve conduit, vein graft, or similar envelope. An alternative approach like fibrin glue has demonstrated equivalent or superior results to suture repair in numerous animal studies and one human study [11], but concerns about lack of tensile strength and secondary nerve gapping persist [11]. Beyond fibrin glue, we have seen poly(ethylene glycol [PEG]) hydrogel improve resistance to gapping, show equivalence to suture, and demonstrate better results than fibrin sealant [8]. The use of photochemical tissue bonding (PTB) represents an even-morepromising technique using a nonthermal, Nd/YAG laser, nonimmunogenic amnion-derived wrap, and a photoactive dye. Animal studies [5, 9] suggest improved electrophysiological outcomes, histologic recovery, and even gait compared to direct suture repair. A more-recent study [3] created a $15 \mathrm{~mm}$ defect in rat sciatic nerves and repaired the defect with reversed isografts. PTB repairs outperformed suture repair for both immediate and delayed (30 days) reconstruction with regard to muscle mass retention and histomorphometric recovery [3]. Animal studies of escalating complexity continue to be performed for this technique, with the hope of human trials commencing shortly.

Other interventions to improve nerve repair and reconstruction outcomes are being investigated, as well, and those mentioned above are by no means an exhaustive list. It also seems likely that no single modality will lead us to the holy grail of normal (or nearly normal) function following proximal or long-segment peripheral nerve injury. Perhaps most importantly, many of these newer techniques can be used concurrently and may ultimately prove complimentary. For example, one can imagine using PTB with allografts, reinforced with fibrin or PEG hydrogel glue, in a patient treated with low-dose tacrolimus postoperatively to improve overall recovery.

Ultimately, we need to ask ourselves "if this injury happened to me, could I still be an orthopaedic surgeon?" Until the answer is yes, we need to keep pushing the clinical and translational research envelope. But someday soon, stitching up a nerve repair or reconstruction may not require a stitch at all.

\section{References}

1. Cho MS, Rinker BD, Weber RV, Chao JD, Ingari JV, Brooks D, Buncke GM. Functional outcome following nerve repair in the upper extremity using processed nerve allograft. $J$ Hand Surg. 2012;37:2340-2349.

2. Elliott RM, Tintle SM, Levin LS. Upper extremity transplantation: Current concepts and challenges in 


\section{From Bench to Bedside}

an emerging field. Curr Rev Musculoskelet Med. 2014;7:83-88.

3. Fairbairn NG, Ng-Glazier J, Meppelink AM, Randolph MA, Wino grad J, Redmond R. Improving outcomes in immediate and delayed nerve grafting of peripheral nerve gaps using light-activated sealing of neurorraphy sites with human amnion wraps. Plast Reconstr Surg. 2016;137:887-895.

4. Griffin JW, Hogan MV, Chhabra $\mathrm{AB}$, Deal DN. Peripheral nerve repair and reconstruction. J Bone Joint Surg Am. 2013;95:2144-2151.

5. Henry FP, Goyal NA, David WS, Wes D, Bujold KE, Randolph MA, Winograd JM, Kochevar IE, Redmond RW. Improving electrophysi ologic and histologic outcomes by photochemically sealing amnion to the peripheral nerve repair site. Surgery. 2009;3:313-321.
6. Isaacs $J$, Browne $T$. Overcoming short gaps in peripheral nerve repair: conduits and human acellular nerve allograft. Hand. 2014;9:131-137.

7. Karabekmez FE, Duymaz A, Moran SL. Early clinical outcomes with the use of decellularized nerve allograft for repair of sensory deficits within the hand. Hand. 2009;4:245-249.

8. Lin KL, Yang DY, Chu IM, Cheng FC, Chen CJ, Ho SP, Pan HC. DuraSeal as a ligature in the anastomosis of rat sciatic nerve gap injury. J Surg Res. 2010;161:101-110.

9. O’Neill AC, Randolph MA, Bujold KE, Kochevar IE, Redmond RW, Winograd JM. Photochemical sealing improves outcome following peripheral neurorrhaphy. J Surg Res. 2009;151:33-39.

10. Ruijs AC, Jaquet JB, Kalmijn S, Giele H, Hovius SE.. Median and ulnar nerve injuries: A meta-anal- ysis of predictors of motor and sensory recovery after modern microsurgical nerve repair. Plast Reconstr Surg. 2005;116:484494.

11. Sameem M, Wood TJ, Bain JR. A systematic review on the use of fibrin glue for peripheral nerve repair. Plast Reconstr Surg. 2011;127:2381-2390.

12. Tanaka K, Fujita N, Higashi Y, Ogawa N. Neuroprotective and antioxidant properties of FKBPbinding immunophilin ligands are independent on the FKBP12 pathway in human cells. Neurosci Lett. 2002;330:147-150.

13. Yan Y, Sun HH, Hunter DA, Mackinnon SE, Johnson PJ. Efficacy of short-term FK506 administration on accelerating nerve regeneration. Neurorehabil Neural Repair. 2012;26:570-580. 